\title{
SUBCLAVIAN LYMPH NODE, PLEURAL AND PULMONARY BIOPSY IN THE DIAGNOSIS OF INTRA-THORACIC DISEASE
}

\author{
By Cotter Harvey, F.R.C.P., and H. P. B. Harvey, M.R.C.P., M.R.A.C.P. \\ From the Thoracic Unit of the Royal Prince Alfred Hospital, Sydney
}

It is axiomatic that enlightened treatment must wait on precise diagnosis. Only in recent years, however, has this principle been fully applied in intra-thoracic lesions. The universal employment of radiology has led to a considerable increase in the range of diagnostic possibilities, and we have been forced to abandon what in the 'good old days' were comfortable pigeon holes in which to place the doubtful chest case. Unresolved pneumonia, pulmonary fibrosis, mediastinal tumour, no longer are these adequate labels, however factual they be. They must be relegated to the diagnostic scrap heap. The policy of watchful waiting is rarely justified, while ' trial and error' techniques such as X-ray therapy, are quite obsolete.

Despite these dogmatic assertions, we must admit that the diagnosis of pulmonary disease appears to be becoming even more difficult. After successively obtaining a careful history and carrying out physical and X-ray examinations by varied techniques together with blood, sputum and biochemical studies, we are often still at a loss for a diagnosis.

As with elsewhere in the body, the question of a biopsy then arises, based on a principle established in another field of endeavour, that one look is worth two finesses. From where may this tissue be obtained in order that we may see precisely what pathological process is at work, and happily also at times, the organism responsible? It is the purpose of this contribution to discuss three of the possible procedures that may be employed. They are (I) the resection of the deep cervical fat pad with its enmeshed lymph glands, now generally known as 'scalene node biopsy'; (2) needle biopsy of the parietal pleura; and (3) biopsy of lung tissue by open thoracotomy.

Other tissue examinations, notably sputum cytology and biopsy obtained by bronchoscopy, are mentioned here for completeness. These are well-established procedures as also, of course, is formal exploratory thoracotomy for the diagnosis of ' solitary' lesions.

We are particularly concerned in this paper, with the diagnosis of pleural effusions and of diffuse pulmonary disease.

\section{Scalene Node Biopsy}

It is well known that differentiation of obscure intra-thoracic disease can sometimes be made by $\vec{\sigma}$ biopsy of enlarged superficial lymph glands. To Daniels ${ }^{1}$, however, must go the credit for ob- $\frac{0}{3}$ serving, in 1949, that when no such glands are available, histological examination of lymph glands embedded in the fatty pad lying between the sterno mastoid and anterior scalene muscles may provide the diagnosis. These glands are connected with those of the superior mediastinum, $ᄋ$ and may thus ' mirror' intra-thoracic disease, pulmonary or mediastinal. Recognition of the value $\vec{D}$ of this procedure has been tardy, though it is increasing in North America. So far, we have not $\overrightarrow{\vec{\theta}}$ found a single reference to it in British journals, n\& for a matter of that, in any recent textbook.

Out of a number of papers in the Americt literature, we would quote from two. Shefts $e t a l: \vec{?}$ in 1953, reported on 187 patients in whom they carried out scalene node biopsy. In 67 , this $\frac{\circ}{\square}$ ' yielded convincing evidence of the identity of $\stackrel{\unrhd}{\square}$ associated intra-thoracic disease which had been $\overrightarrow{\overrightarrow{0}}$ previously undiagnosed despite application of the 3 generally used non-surgical diagnostic measures.' In 1954 Carstensen et $a l^{3}$ reported their experiences in Sweden, with 56 cases. 'Out of 45 흑 typical or strongly suspected cases of sarcoidosis without palpable lymph nodes, the diagnosis was $\frac{3}{3}$ confirmed in 30 (66 per cent.). The method published by Daniels in 1949 seems not to have been $\frac{\text { o }}{3}$ duly appreciated.'

\section{Technique}

The procedure is a simple one, carried out under local anaesthesia, though some care is re-o quired to locate the fat pad. It lies in front of the $N$ anterior scalene muscle, and usually a prolongation $N$ may be found going down into the superioro mediastinum. All this tissue is removed if possible, 0 and in it are found constantly several small lymph nodes, sometimes pin-head in size. At this the $\stackrel{?}{+}$ morbid anatomist may at first complain, but he is 0 very often able to make an exact diagnosis from

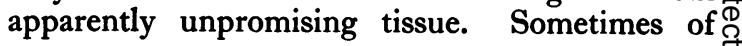


TABLE I

SCalene Node BIOPSY

Royal Prince Al.fred Hospital

JULY 1955-JUNE 1957

\begin{tabular}{|c|c|c|c|}
\hline Carcinoma & . & 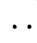 & \\
\hline Sarcoidosis $\quad \ldots$ & . & .. & . \\
\hline $\begin{array}{l}\text { Lymphosarcoma } \\
\text { Hodgkin's Disease }\end{array}$ & . & . & . \\
\hline $\begin{array}{l}\text { Hoagkin s Disease } \\
\text { Non-Specific }\end{array}$ & .. & $\because$ & . \\
\hline No Iymph Gland & .. & $\therefore$ & . \\
\hline $\begin{array}{l}\text { Total } \\
\text { Percentage I }\end{array}$ & & - & . \\
\hline
\end{tabular}

course, these lymph glands are grossly enlarged and easily visible to the naked eye.

During the past two years, this procedure has been carried out on $5^{\circ}$ patients in our unit, in 25 of whom it has been the means of establishing an otherwise obscure diagnosis. See Table r. The following are illustrative case reports :

Case I

Mrs. V. M., aged 28, housewife, noted in April, I954, that she was losing her voice. In mid-June she had a feverish attack, and as there was no improvement in her voice, she saw a laryngologist. He found a left recurrent nerve paralysis, and advised an X-ray of the chest. However, the patient felt better and delayed having this done until July 30 , when it was found she had a large effusion in the left hemithorax, with heart displaced to the right. On questioning, she admitted shortness of breath on 'heavy exertion' but no cough or pain: $1,500 \mathrm{cc}$. of straw-coloured fluid were aspirated following which an X-ray showed, in addition to a pneumothorax, and a fluid level, infiltration in the collapsed left lung. She was admitted to hospital as a probable tuberculous pleurisy with effusion, on August I I.

There she was afebrile, her Mantoux reaction was positive and leucocytes numbered 14,600 per cubic millimetre in her peripheral blood. No organisms were recovered from the pleural fluid, and as she had no sputum, the results of a gastric lavage were submitted for culture. Meanwhile treatment was commenced with streptomycin plus P.A.S.

Three weeks later, as fluid was still reforming, it was agreed that the diagnosis, already dubious in view of the recurrent laryngeal palsy, needed reappraisal. Bronchoscopy was uninformative, there was no ovarian mass to support a diagnosis of Meig's syndrome, and thoracotomy was considered. It was decided to precede this by a scalene node biopsy. This showed the presence of adeno-carcinoma.

The patient was allowed to go home, where her condition rapidly deteriorated and she died in February, 1955.

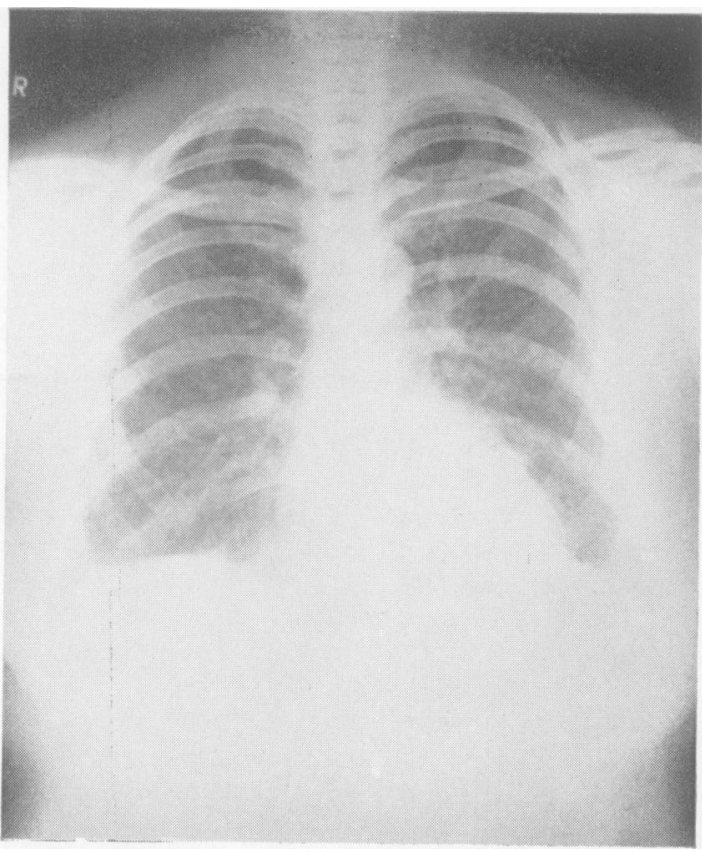

FIG. I.-X-ray film of Case 2 showing diffuse bilateral infiltration (sarcoidosis).

For this patient both diagnosis and prognosis were sealed by the biopsy. It may be noted here that some writers commend this procedure as a test of the operability of all proven as well as suspected cases of bronchial carcinoma. Though it could not be urged as a routine it certainly has, in our hands, been the means of avoiding useless surgery in a number of doubtfully operable cases.

\section{Case 2}

Mrs. E. T., aged 4I, housewife, was first seen on February 23, 1954. She had previously been treated for ' nerve trouble' and for ' fibrositis' of neck and shoulders. Her visit resulted from her recall after a mass X-ray survey. A large ray taken on February 10, I954, showed a fine disseminate infiltration involving practically the whole of both lungs. (Fig. I.)

On questioning she admitted slight shortness of breath for I 8 months, but she had no cough. She was a robust woman weighing i I stone $3 \mathrm{lb}$., and no abnormal physical signs were found on examination.

In hospital she did not react to the Mantoux test; other tests were uninformative.

A biopsy was obtained from the deep cervical fat pad; this revealed a lymph gland showing the typical histological picture of sarcoidosis. (Fig. 2.)

Later cortisone therapy given for a probably 


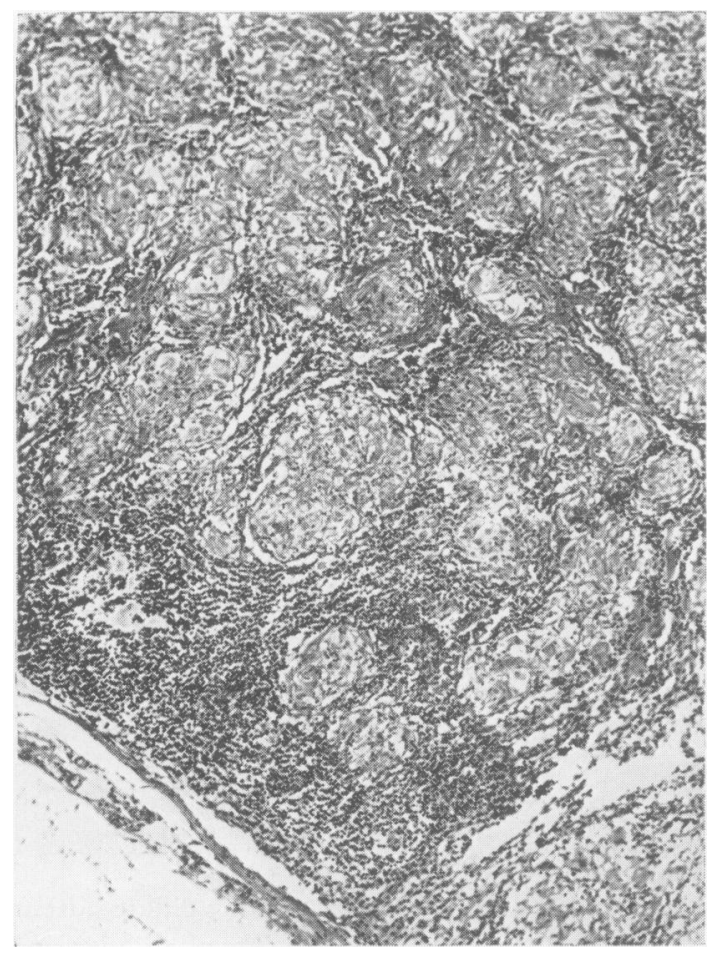

FIG. 2.-Section of scalene lymph node containing sarcoid follicles (Case 2). (H. \& E. $\times 75$.)

unrelated ' shoulder-hand syndrome ' was followed by complete resolution of the lung changes.

\section{Comment}

Scalene node biopsy is particularly valuable in the diagnosis of diffuse pulmonary infiltrations, in hilar adenomegaly and in doubtful mediastinal masses. We have found the greatest yields from cases of sarcoidosis and bronchial carcinoma. It is free from troublesome complications, and it has now a definite place in our diagnostic armamentarium.

\section{Pleural Biopsy}

Though there are only two brief reports ${ }^{4,5}$ of needle biopsies of the parietal pleura in the literature, we have found this a useful procedure particularly in the elucidation of obscure pleural effusion. We have employed it on 42 occasions, and obtained positive histopathological proof of carcinoma or tuberculosis in 14 cases. Though this does not seem a particularly high yield, it was an invaluable one, for in nearly all these patients precise diagnosis was lacking despite numerous investigations. In some cases, the diagnosis may have been inferred from collateral evidence, but this is not always satisfactory, either to the patients, or to the exact-minded physician. It is, for instance, comforting at least to know that the young man whom you are committing to sanatorium care, and six months absence from work, does in fact have a tuberculous pleuritis. Moreover, in any group, this procedure may be the only way short of thoracotomy, of distinguishing between carcinoma, tuberculosis and other inflammatory effusions.

Some authors advise open thoracotomy in preference to needle biopsy in order to obtain a portion of the pleura for histological examination. While freely admitting that this operation affords a higher positive yield, it is a surgical procedure. We would plead that the simpler and safer acupuncture be given priority, reserving the surgeon's help for later, if necessary.

Fleishchman et al. ${ }^{6}$ have recently sought to obtain this information by thoracoscopy, but as they admit positive results with equal frequency from both parietal and visceral pleura there appears to be little advantage in this manoeuvre over the simpler one we employ.

\section{Technique}

In nearly every case the biopsy was performed to elucidate the nature of an obscure pleural effusion. The procedure is simple in such patients. The chest wall is anaesthetized and its thickness accurately measured on the anaesthetizo ing needle. A Franseen needle with stilette in place is introduced to a depth of $5 \mathrm{~mm}$. short of the pleural cavity. A syringe, as for injecting haemorrhoids, is then affixed to the exterior coring portion of the needle. With a combined screwing and advancing motion performed whilst suction is maintained on the syringe the pleural cavity is entered.

When fluid is present this gushes into the barrel of the syringe and the needle is withdrawn. The gush of fluid is also valuable in washing the biopsy specimen into the syringe, so that it cannot be lost on withdrawal of the needle.

The procedure is more difficult when the pleura is dry but still safe and relatively easy. No complications have occurred from any of these procedures.

There are four possible findings:

I. No pleura is obtained. This is the invariable result from normal pleura, which being thin and taut is no more susceptible to this type of biopsy than would be a rubber balloon. It simply splits and allows the needle past.

No pleura has also been obtained from several cases of carcinomatous effusion. It is not clear whether this was because the parietal pleura was not involved when the biopsy was performed, though probably this was the case.

2. Various types and degrees of non-specific 


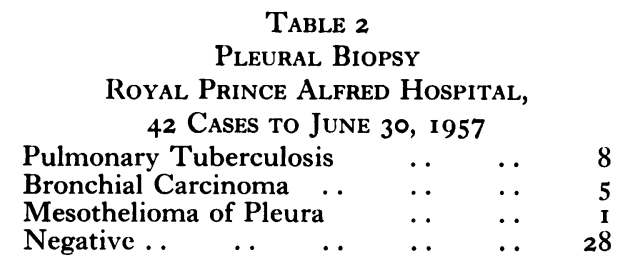

organizing pleuritis are found. This was so in our cases of simple empyema and was also common in tuberculosis. It was also seen on two occasions in cases later proven to be carcinomatous.

Neither of these findings are diagnostic nor exclude conclusively carcinoma or tuberculosis.

3. Typical tuberculous granulation tissue is recovered, in which, on staining, acid fast bacilli may be found.

4. Neoplastic, usually carcinomatous, tissue is obtained.

The following cases illustrate the value of this precedure.

\section{Case 3}

A woman of 47 years insidiously developed a right pleural effusion. It was at first straw coloured with the characterization of an exudate, but after two tappings it was consistenly blood stained. It contained no acid fast bacilli. Her Mantoux was positive, her sputum negative for acid fast bacilli on three occasions and for carcinoma cells once. Bronchoscopy was negative.

In addition she had vague colicky abdominal pain, and occult blood was present in her stools, though full barium studies of her G.I. tract and sigmoidoscopy showed no abnormality.

It was felt that she had a malignant pleural effusion secondary to carcinoma of the intestine, but as the effusion could possibly have been tuberculous or secondary to pulmonary infarction and she was in excellent general health, it seemed hard to deny her laparotomy. However, a pleural biopsy showed a small rosette of carcinoma cells. This was thought to be secondary carcinoma from gut, and in view of the later development of hepatomegaly and abdominal distension this seemed likely.

She has recently died and the post mortem report revealed a carcinoma of the small intestine.

\section{Case 4}

A middle-aged man had been known to have a ' scar' at the apex of his left lung for some years. His Mantoux test was positive. When he developed a right pleural effusion at the age of 49 it seemed reasonable to assume this to be of tuberculous

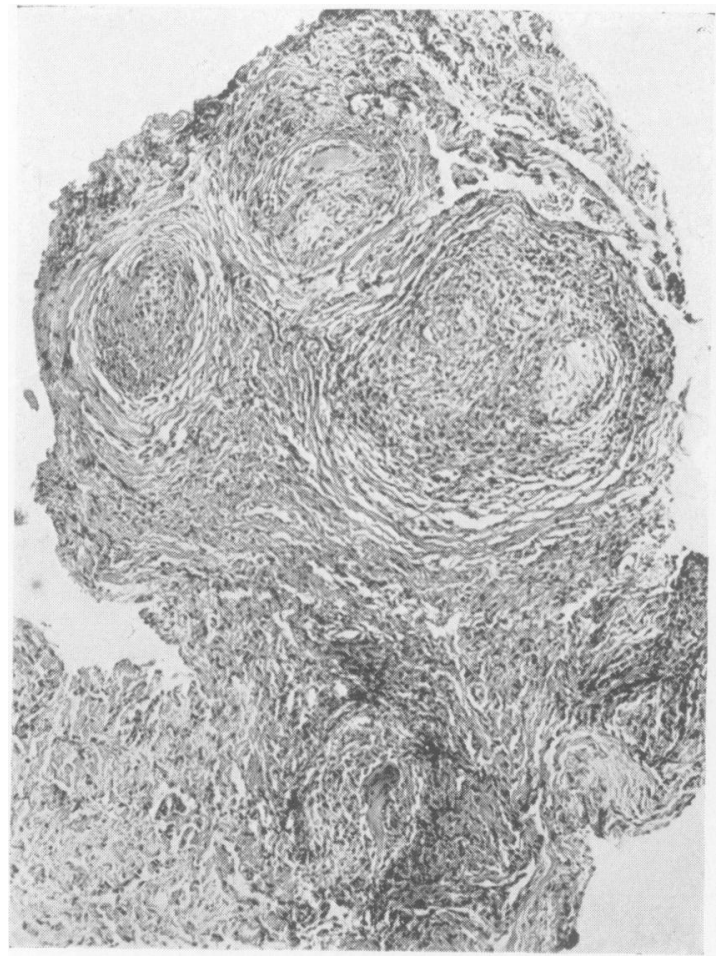

FIG. 3.-Section from pleural biopsy showing ıypical tubercles (Case 4).

origin. The fluid was an exudate but no acid-fast bacilli could be recovered from it or repeated sputum specimens.

When the fluid cleared and then recurred under adequate anti-tuberculous chemotherapy, strong suspicions of carcinoma were aroused. Bronchoscopy was negative and no carcinoma cells were found in the sputum.

A pleural biopsy in this man showed an obvious piece of tuberculous tissue. (Fig. 3.)

In this case, after six weeks uncertainty, the mounting anxiety of patient, relatives and clinicians was thus completely resolved.

He has since made an excellent recovery.

\section{Case 5}

A man of $5^{6}$ years had cough, sputum, loss of weight and chest pain, with an X-ray showing pleural thickening and periostitis of the rib with contraction of the left hemithorax.

Sputum examination for acid-fast bacilli and carcinoma cells was non-contributory. His Mantoux was positive and bronchoscopy showed nothing abnormal.

By pleural biopsy a specimen containing a clump of carcinoma cells was obtained. (Fig. 4.) 


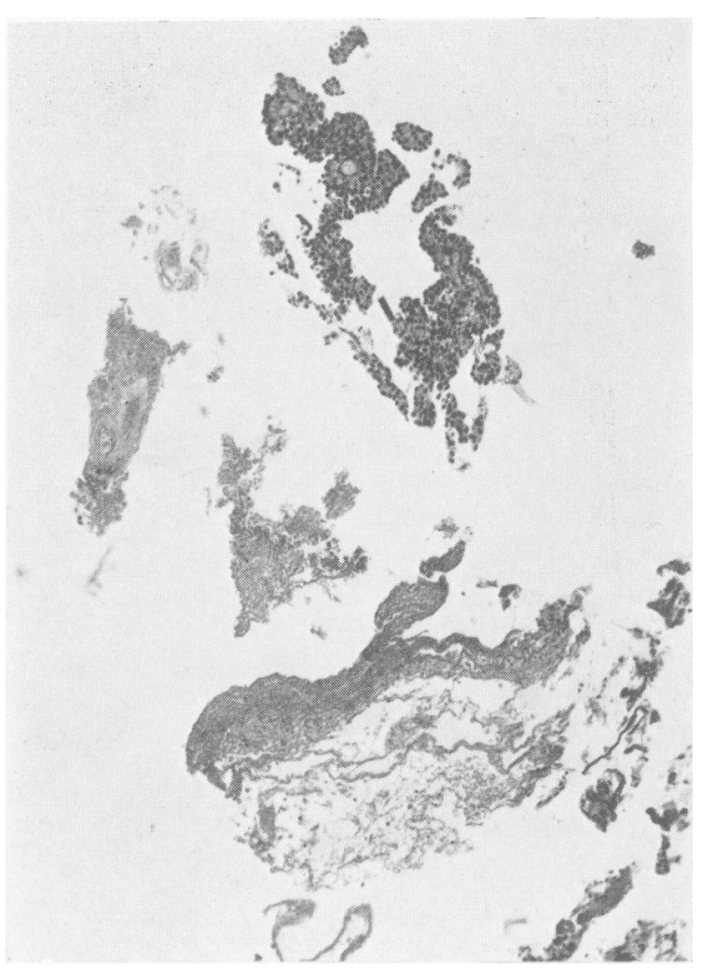

FIG. 4--Section from pleural biopsy showing clumps of carcinoma cells (Case 5). (H. \& E. $\times 75$.

\section{Case 6}

A young man of 28 years had a rather atypical pleural effusion with prolonged malaise and fever. He had, in fact, a history of old Pott's disease and tuberculous pleuritis was the most likely diagnosis. It could not be proven from the fluid or sputum, however, and his pyrexia and malaise made no improvement after many weeks on streptomycin and I.N.H.

In view of an odd mediastinal shadow, lymphosarcoma and other sinister diagnoses were being offered when a pleural biopsy showed granulation tissue in which acid-fast bacilli were demonstrated by Ziehl-Neelsen stain.

\section{Comment}

In our hands, needle biopsy of the parietal pleura has given us a firm diagnosis in 14 cases of pleural disease where other available methods had failed. We now recommend its use long before this late stage has been reached.

In many other cases it has not been of help, but in none has it been harmful.

\section{Lung Biopsy}

This is the most formidable of the three procedures we are discussing. It may, however, be

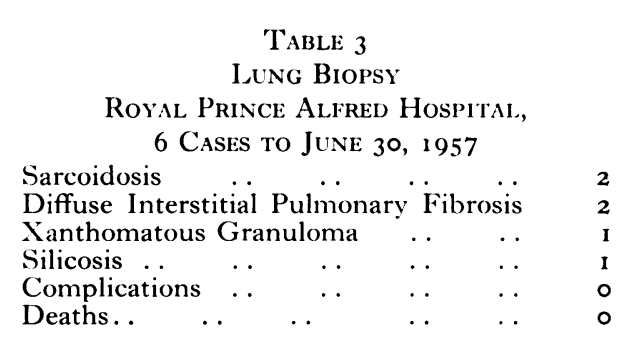

the only way of obtaining a definite diagnosis in a patient with diffuse bilateral pulmonary disease, and we feel it is justified in selected cases. It is admitted that it gives a higher diagnostic yield than scalene node biopsy-in our small group of six cases (Table 3 ) this was roo per cent.- - but we do not yet give it priority, as it appears morc hazardous, and more than one patient has refused to submit to the operation.

Technique (contributed by Mr. Alexander Grant, thoracic surgeon)

General anaesthesia is preferred for the comfort of the patient, and the lung can be more readily expanded at the end of the operation, if desired.

As the disease is usually generalized, the right antero-lateral area is chosen for ease of access. ${ }^{7}$ An intercostal incision, 4 to $5 \mathrm{in}$. in length, is made in the line of the $5^{\text {th }}$ intercostal space, but no rib or cartilage is removed. A small Tuffier (child's size) retractor is inserted and a portion of lung selected by sight and palpation. A representative piece is removed, and the raw area securely closed with fine catgut continuous sutures, to ensure complete vascular and broncho-alveolar occlusion.

A small intercostal catheter is inserted from the space below, and the wound closed. The biopsy specimen should be submitted both to histological and bacteriological examination. An X-ray film of the chest is taken next day, and if the lung is fully expanded, the tube is removed and the patient is allowed up. Sutures are removed on the eighth day after operation.

We would draw attention to the medico-legal importance of lung biopsy in a case of disputed ' dust disease.' One such already appears in our series, and American authors are finding pneumonokonioses not infrequently in this way.

We offer one case history, which was a fascinating diagnostic problem and which had been variously labelled by many specialists, without success.

\section{Case 7}

Miss J. M., a nursing sister, was first seen in March, 1955. She had not been really well since an attack of influenza and a right-sided pleurisy 


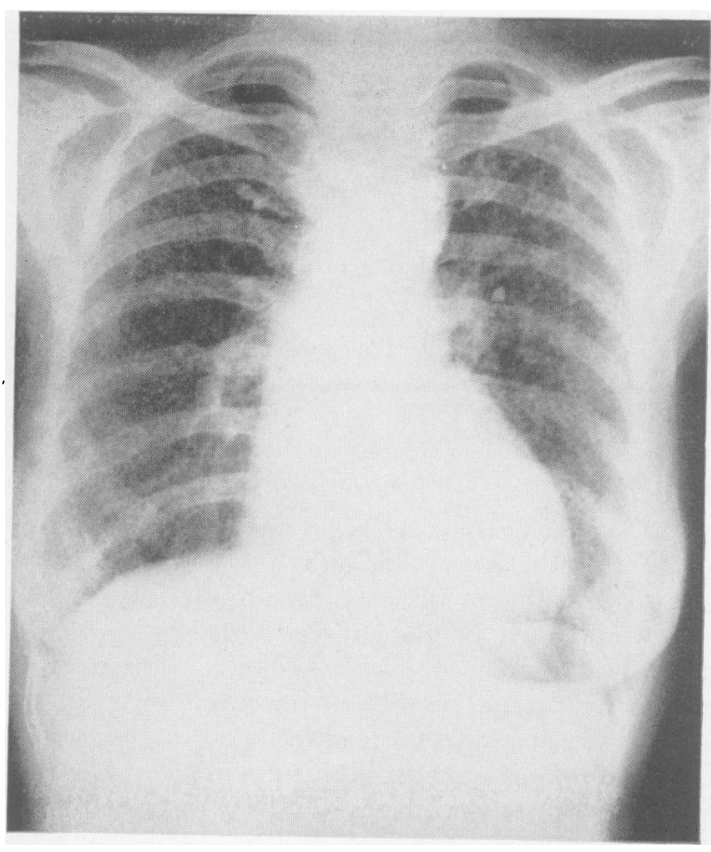

FIG. 5.-X-ray film of Case 7 showing exccnsive bilateral nodular infiltration (xanthoma).

I 8 months previously. In March, 1954, she had been treated for peripheral neuritis.

Since this time she had suffered from indigestion with anorexia and loss of weight. She had a slight cough, but complained only of great fatigue, though she continued on duty. Later, dyspnoea was noticed, though it was never an outstanding symptom.

She had been fully investigated after the X-ray film of her chest had shown a fine discrete nodular infiltration throughout both lungs, 'suggesting miliary tuberculosis.' (Fig. 5.) There were also areas of osteoporosis in the X-ray films of the long bones, particularly radii and ulnae and metacarpals. Her Mantoux test gave a positive reaction. Sputum and gastric lavage failed to yield acidfast bacilli on culture. Her blood count was uninformative but the erythrocyte sedimentation rate was raised to $20 \mathrm{~mm}$. in one hour. The serum calcium was $10.5 \mathrm{~g}$. per cent., and serum protein $9.5 \mathrm{~g}$., with albumin $4 . \mathrm{I}$ and globulin 5.7 per cent.

Scalene node biopsy revealed only a ' slight increase in the number of phaogcytic cells.' Respiratory function studies 'indicated severe pulmonary disability, typical of pulmonary fibrosis.'

A provisional diagnosis of sarcoidosis was given, and the patient remained at work. Eighteen months later, the radiological picture of her lungs was unchanged, and she was reasonably well, though her capacity for work was failing. In an

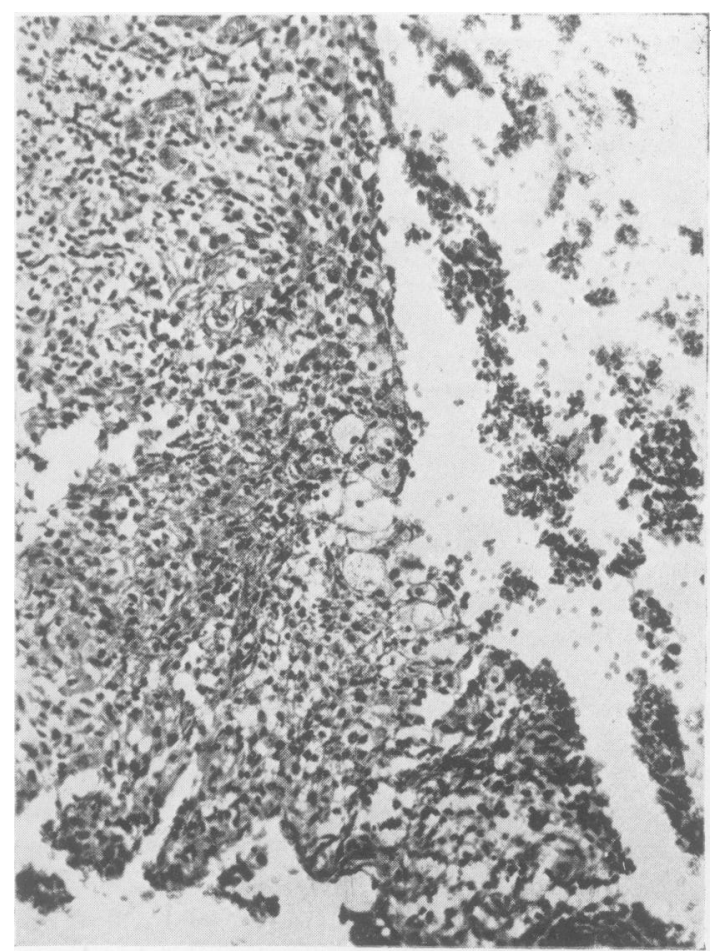

FIG. 6.-Portion of lung biopsy from Case 7 showing cellular components of the infiltration, including lipoid histiocytes. (H. \& E. $\times$ 300.)

endeavour to clinch the diagnosis, lung biopsy was now carried out. The histological appearances were the subject of controversy among local pathologists, until Professor Gough, of Cardiff, kindly supplied us with the correct diagnosis. 'I think this is xanthomatous granuloma. Xanthoma cells are prominent in the lung, occurring here and there in sheets. The absence of eosinophils does not, I think, invalidate the diagnosis.' (Fig. 6.)

Since then the areas of osteoporosis in the long bones have become more extensive and map-like, giving further confirmation of the diagnosis.

In such a case, lung biopsy would appear to be fully justified, though it has been too late to permit of any effective therapy (steroids were exhibited without avail).

Complications, and an occasional fatality have been reported, 8,9 but we regard this biopsy as having a definite, though limited, place in the diagnosis, and prognosis of diffuse pulmonary lesions. ${ }^{10}$ Also, as stated earlier, it may have medico-legal implications.

\section{Summary}

I. Accurate diagnosis of pulmonary and mediasContinued on page 221 . 
almost hopeless and very few recoveries have been recorded.

One of the first cases recorded in the English literature, was by Wright, in I935, and his concluding remarks are most appropriate. 'It would appear that routine visualization of the stomach by barium is desirable in all cases of crushing injuries to the chest, if the surgeon is to receive the case early and not when some catastrophe such as acute strangulation has rendered his help imperative, but has vitiated the chance of a successful outcome to a difficult operation.'

\section{Summary}

A personal experience of ten cases of indirect rupture of the diaphragm with closed trunk injuries is presented.

The case histories are given in chronological order and in some detail because as well as illustrating the features of the condition, they give a good account of the author's education in its management.

It is considered that the most important single factor in making the diagnosis, is the recognition of the plain chest X-ray appearance. Once this is understood, the diagnosis will rarely be missed.

With this in mind, a plea is made for early routine plain chest X-ray of all cases following severe trauma to the trunk, particularly those with midriff pain and signs of reduced function of one or other lung base.

Surgical treatment is clearly indicated as a matter of urgency in all cases, because of the high mortality if gangrene has occurred, compared with a negligible one before strangulation.

\section{Acknowledgements}

To the physicians and surgeons of the Royal Adelaide Hospital and Adelaide Children's Hospital, who referred cases for treatment.

To Mr. Alan Britten Jones, for permission to include his case which was only seen by the author in consultation.

\section{BIBLIOGRAPHY}

BUGDEN, WALTER F., et al. (1955), Ann. Surg., 142, 851 CARTER, B. NOLAND, et al. (195I), Amer. Y. Roentgenol., 65, 56 CARTER, B. NOLAND, and (GINOEFFI, J. (1948), Ann. Sirg.

I28, 2 IO.
DUGAN, D. J., ard SAMSON, P. C. (1948), f. thorac. Siurg.,

HAMIL 77Ó. 78, 686

HARRINGTON, S. W. (1945), Ann. Surg., 122, 546.

HARRINGTON, S. W. (1933), F. Amer. med. Ass., ror, 987 HEDBLOM, C. A. (1925). Ibid., 85, 947.

MANLOVE, C. H., and BARÖNOFSKY, I. D. (1955), Surgery, $37,461$.

MARSHALL and SANFORD, et al. (1956), Postgrad. med. Y., I9, 60

SCHNEIDER, CHARLES F. (I956), Amer. F. Surg., 91, 290

STRODE, F. C., and VANCE, C. A. (1953), Ann. Surg., 137, foo. IVRIGHT, R. D. B. (1935), Brit. med. $\mathcal{Y}$., ii, 577 .

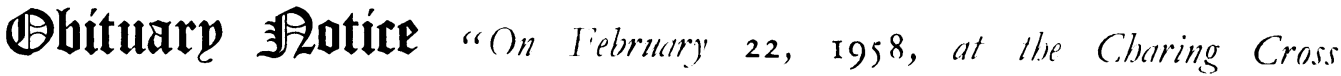
Hospital, Toby' Levitt, M.A.(Cape Ton'n), I'.R.C.S.ling., passed an'(!)' peacefully' after a long illness, bravely evidured."

It is with regret that we record the death of Dr. Levitt, who did a great deal of work for the Fellowship, and whose demonstrations and lectures were universally appreciated by those who attended his classes. Our sympathy is extended to his sister.

Continued from page 209--Subclavian Lymph Node by' Cotter Harrey and Peter Harvey.

tinal disease may necessitate consideration of biopsy procedure.

2. Three possibilities are discussed:

(a) Scalene node biopsy, especially for widespread pulmonary infiltrations and mediastinal adenomegaly.

(b) Pleural biopsy for pleural effusions.

(c) Lung biopsy for diffuse pulmonary infiltrates otherwise undiagnosable.

3. 'These procedures have minimal morbidity and they merit more widespread use.
4. Cases are reported to illustrate the value of these methods.

\section{REFERENCES}

. DANIELS, A. ('. (1949), Dis. Chest, 16, 360.

2. SHEFTS, L. M., et al. (1953), Amer. Rev. Tuberc., 68, 505.

3. CARSTENSEN, B., et al. (1954), Dis. Chest., 25, 443.

4. SOTCLIFFE, W. D., et al. (1954), Ibid., 26, 551 DE FRANCIS, N., KLOSK, F., and ALBANO, E., N. Eng. f. Med., 252, 998, 955

6. FLESHMAN, S. J., et al. (1956), Thorax, I I, 324

7. KLASSEN, K. P., et al. (1949), Arch. Surg. (Chicago), 59, 694 9. EFFLER, D. B., et al. (1955), Amer. Rev. Tuberc., 71, 668.

9. THEODOS, P. A., et al. (I955), Dis. Chest, 27, 637.
I0. STOREY, C. F., and RFY'NOLDS, B. M. (1953), Ibid., 23, 357 